\section{LA CATEGORÍA DE GÉNERO EN LA TEOLOGÍA FEMINISTA DE TERESA FORCADES}

\section{Elizabeth Bellon Cárdenas}

Y Jesús le respondió: -Tú debes nacer de nuevo. Nicodemo sorprendido:-¿Cómo puede un adulto entrar de nuevo en el útero de una mujer? Jesús dice: -Este no es el camino del renacimiento. Tienes que nacer de nuevo del agua y del espiritu. Para mí esto significa ser queer. Teresa Forcades

\section{INTRODUCCIÓN}

En estas líneas presento avances de un proyecto en curso, ${ }^{1}$ cuyo objetivo es comprender diversas prácticas y creencias religioso/espirituales relacionadas con "el poder" y "lo femenino" en mujeres que se autoadscriben a colectividades religioso/espirituales -institucionalizadas y no institucionalizadas - y que ocupan una posición de "guía" o "liderazgo" dentro de las mismas.

A partir de la condición contemporánea de "pluralidad religiosa" y con base en una metodología cualitativa, en esta primera etapa se pretende comparar los procesos de empoderamiento de personas autoadscritas a diferentes comunidades

$1 \mathrm{El}$ proyecto de investigación individual al que se refiere este texto se titula "Liderazgo femenino en la pluralidad religiosa contemporánea", CC-2015-0684, Universidad Autónoma de la Ciudad de México (UACM), plantel San Lorenzo Tezonco. para problematizar las categorías de "género", "religión" y "poder". Si bien en esta fase se trabaja con mujeres líderes cristianas, tanto en México como en el extranjero, en posteriores etapas se prevé examinar las prácticas y creencias de personas vinculadas con diversas identidades sexo/ genéricas y religioso/espirituales, así como con creyentes o practicantes regulares y no creyentes.

Mi interés no sólo estriba en visibilizar de qué manera las mujeres se insertan en jerarquías religiosas institucionalizadas o en comunidades espirituales no institucionalizadas, sino en reconocer de qué se constituye "lo femenino" en contextos históricos y culturales específicos, analizando las formas en las que se representa y se ejerce el "poder". Como en otros ámbitos, el estudio de las creencias y prácticas religioso/espirituales desde una perspectiva de género revelará, de manera clara, características fundamentales de la dinámica social.

El supuesto general que guía la investigación es que en la actualidad las creencias y prácticas religioso/espirituales de las personas o "sujetos de género" (Butler, 2007) cuestionan y deconstruyen la "jerarquización" o "binarismo" masculinofemenino establecido por las "religiones institucionalizadas" (Hervieu-Léger, 2005; Berger, 2012) o "mayoritarias" (PEW, 2012), en México y el mundo. Por ello, resulta relevante indagar la forma en la que se concibe y se vive "lo femenino" y "el poder", más allá de los “dualismos" hombre-mujer, mente-cuerpo, razón-emoción, persona-divinidad, público-privado, entre otros.

La opresión y dominación que han ejercido ciertas instituciones religiosas tradicionales 
en la sociedad, la creciente mercantilización y virtualización de las creencias aunada a la estandarización de narrativas y a la conformación de redes de pares a escala mundial (Hervieu-Léger, 2006: 63-64), además del rechazo al monopolio institucional de la verdad, la tendencia hacia la individualización de las creencias y el potencial "liberador" y "subversivo" de las mismas en contextos no institucionalizados, invitan a esbozar algunas respuestas.

Al comienzo de esta búsqueda nos acercamos a la biografía y obra de Teresa Forcades, monja benedictina, catalana, médica, activista y teóloga feminista contemporánea. En este escrito adelanto una reflexión a partir del diálogo que ella misma establece con autoras y autores vigentes como Judith Butler, Jacques Lacan o Paul B. Preciado. El propósito es presentar, de manera sintética, el planteamiento general de la investigación y discutir ideas centrales en torno a la articulación entre la categoría de género y la teología feminista de Forcades. Se concluye que tanto su teología como su liderazgo destacan por sus pasajes disidentes entre los espacios religioso, político y social; tránsitos posibles y necesarios ante las demandas del siglo XXI.

\section{JUSTIFICACIÓN Y MARCO CONCEPTUAL}

Believing without belonging. Belonging without believing. Peter Berger

"No hay una sola actividad humana que no apele al creer y lo suscite" (Hervieu-Léger, 2005: 169), por ello las religiones siempre han tenido, tienen y probablemente tendrán un lugar significativo en la vida social. La resistencia de algunos científicos sociales a investigar este campo de estudio ha estado presente durante el siglo XX debido, en principio, a la teoría de la secularización (Weber), pero también porque la tendencia hegemónica en el estudio de las religiones ha sido occidental, etnocentrista, eurocéntrica y patriarcal.

Considero provechoso indagar de manera crítica y alternativa las diversas formas en las que personas e instituciones producen y reproducen significados sobre lo social a través de creencias y prácticas religioso/espirituales en el mundo contemporáneo. Si bien existen ya valiosos estudios cuantitativos y cualitativos en torno a agrupaciones religiosas concretas, tanto a escala local como global, aún falta describir de forma eficaz los procesos de empoderamiento y resignificación de "lo femenino" y del "poder" desde una perspectiva transdisciplinaria, crítica, comparativa y de género.

Puesto que la pluralidad siempre implicará luchas simbólicas por el reconocimiento y la reconfiguración de la identidad, es importante registrar, describir e interpretar prácticas y creencias religioso/espirituales que producen sentido colectivamente y, también desde este ámbito, construyen socialmente la realidad.

\section{De la secularización a la pluralidad religiosa}

Contrario al "desencantamiento del mundo" previsto por la teoría de la secularización (Weber), hoy observamos que la tradición es parte de la modernidad; lo secular y lo religioso coexisten (Hervieu-Léger, 2006; Berger, 2012); “el mundo, con algunas notables excepciones - Europa-, es tan religioso como siempre ha sido, y en algunos lugares 
es más religioso que nunca - fundamentalismos-". (Berger, 2001: 445)

La legitimación de las creencias colectivas se construye cada vez menos sobre dogmas rígidos establecidos por instituciones religiosas, y cada vez más a partir de una apropiación creativa, individual y múltiple de una tradición (Hervieu-Léger, 2005); "creyentes de todos los orígenes afirman identidades religiosas compuestas, en las cuales son cristalizadas las sucesivas y acumulativas etapas de su personal búsqueda" (Hervieu-Léger, 2006: 60). Asimismo, desde América Latina, culturas "trans-modernas" irrumpen desde la "exterioridad alternativa de lo siempre distinto", asumiendo los desafíos de la modernidad, y aún de la post-modernidad europeonorteamericana, pero "desde otro lugar" (Dussel, 2005: 17), personificando el "rol subversivo" de la religión en el siglo XXI (Löwy, 2013).

En consecuencia, a partir del debate siempre abierto entre especialistas por definir los límites y el sentido de las religiones en la actualidad (razón-magia, ciencia-fe, modernidad-tradición, fanatismo-ateísmo, secularización-pluralización, religión-creencias, etc.), la perspectiva teórica con mayor potencial heurístico que por lo pronto orienta este trabajo es aquella que apela a la pluralidad y a la diversidad (Hervieu-Léger, 2006; Blancarte, 2010; Berger, 2012). Pero, ¿resulta significativo para la comprensión de nuestras realidades sociales explorar las características del "liderazgo femenino" en el contexto religioso actual?

Liderazgo de las mujeres desde la teoría de género La teoría de género y el feminismo han aportado elementos para un análisis crítico sobre la relación de "opresión patriarcal" entre hombres y mujeres, así como sobre los procesos de "empoderamiento" (Lagarde, 2012) de cuerpos con sexo/género/ deseo y performance "de mujer" (Butler, 2007). Se han llevado a cabo numerosas investigaciones sobre grupos religiosos, pero resultan escasas las que examinan la participación diferenciada por sexo. Dichos acercamientos destacan la presencia mayoritaria de las mujeres en los grupos religiosos, desarrollando actividades para el mantenimiento de la organización como la enseñanza y la predicación, o las relacionadas con la limpieza y arreglo del lugar de culto, pero en la mayoría de los casos siguen sin acceder a puestos de dirección, administración o toma de decisiones (Juárez y Ávila, 2007: 167)

La subordinación de lo femenino a lo masculino - contraria al discurso gubernamental sobre la "equidad" o al discurso teológico de la "unidad en la diversidad" - perdura en este campo. Todavía en años recientes, teólogas feministas en Europa, Estados Unidos y América Latina (por ejemplo, Gebara en 1994; Reynolds y Birch en 2005; Traupman, Prejean y Akers en 2008; Forcades en 2009) han sido "excomulgadas", "silenciadas" o "llamadas al orden" por el Vaticano debido a sus señalamientos de que la Iglesia católica es misógina y patriarcal, de que mantiene una doctrina andro y antropocéntrica, así como por pronunciarse contra la pena de muerte, a favor de la interrupción legal del embarazo, la eutanasia pasiva, del matrimonio igualitario y de la igualdad de oportunidades para mujeres que aspiren al sacerdocio o a posiciones de autoridad dentro de la jerarquía eclesial.

Mi intención no sólo es explorar de qué manera las mujeres "luchan" al interior de las 
jerarquías eclesiásticas institucionales, sino también reconocer de qué se constituye "lo femenino" en contextos históricos y culturales específicos (Scott, 2006; Butler, 2007). Si bien el género ha sido una categoría relacional necesaria para denunciar la dominación patriarcal "universal” y contribuir a la "liberación" de las mujeres no como "seres-paraotros" sino como "seres-para-sí" (Lagarde, 1996), advierto que "lo femenino" ya no parece ser una noción estable, y su significado es tan problemático, vago y ficticio como "mujer"2 (Scott, 2006: 137-138; Butler, 2007: 38; Preciado, 2011: 13-14).

Desde la teoría feminista se propone el modelo de la "sororidad" como una forma de interacción social y participación política de las mujeres; "alianza" que, reconociendo la especificidad y diversidad entre ellas, valida de manera recíproca y temporal la autoridad de las otras como parte de un "poder compartido" y una "acción conjunta" (Lagarde, 2012: 526). Bajo el cuestionamiento de estereotipos y dicotomías acerca del estilo de liderazgo femenino y masculino, así como del ejercicio del poder por mujeres y hombres (verticalhorizontal, competencia-colaboración, personaequipo, pirámide-red, subordinación-inclusión, patriarcal-sororal, etc.), considero pertinente analizar, por un lado, la manera en la que están ejerciendo el poder "mujeres lideresas" o "guías feministas" que

2 Siguiendo a Scott anticipamos que "la identidad como un fenómeno continuo, coherente e histórico resulta ser una fantasía - fantasy echo - [...] La palabra distintiva mujeres hace referencia a tantos sujetos, diferentes e iguales, que se convierte en una serie de sonidos fragmentados, inteligible sólo para el oyente, quien —al especificar su objetoestá predispuesto a escuchar de una cierta manera" (Scott, 2006: 137, 138). Para Preciado, "la heterosexualidad y la homosexualidad no existen, son ficciones políticas" (en Curia, 2015). se autoadscriben a distintas tradiciones religioso/ espirituales o creencias colectivas contemporáneas, y por otro, dilucidar la forma en la que se problematiza "lo femenino" y "el poder" en contextos históricos y culturales específicos.

\section{METODOLOGÍA}

$$
\text { Après n'avoir plus vu de religion nulle part, }
$$
on découvrait du sacré partout.

Danièle Hervieu-Léger

Se eligió la metodología cualitativa debido a que considero sustancial aproximarme, a través de sus propios relatos, a la trayectoria y experiencias de vida de mujeres que han reflexionado críticamente sobre sus creencias y ocupan una posición de liderazgo en sus colectividades, en el marco de la pluralidad religiosa contemporánea.

Reconociendo sus ventajas y limitaciones, en esta primera etapa del trabajo de campo se elabora la evidencia empírica a través de técnicas de investigación cualitativas como la entrevista en profundidad y la observación participante, mientras que la interpretación de la información se realiza con base en la técnica de análisis de contenido cualitativo.

Para seleccionar a las mujeres entrevistadas se diseñó un muestreo teórico que de manera intencional y diversificada permite profundizar en casos significativos. Con base en el marco conceptual, las variables que se consideran más significativas son: género, edad, adscripción religiosa, lugar de residencia y tipo de liderazgo.

Se pretende construir categorías que no reproduzcan la "asimetría de género", o bien el 
"sistema sexo/género" heteronormativo, para evitar imponer rígidamente límites a la caracterización de las personas creyentes, por lo que se retoma a aquellas que me parecieron más sugerentes desde una mirada transversal.

Derivado de lo anterior, en esta primera fase de la indagación y en consonancia con los intereses teóricos del planteamiento, se registra, primero, la experiencia de "mujeres" autoadscritas a "creencias religioso/espirituales" cristianas, de diferentes segmentos etarios, que residieran en México o fuera del país, que se autoidentificaran como "feministas" y que ocuparan una posición de "liderazgo". Respecto del procedimiento, se llevó a cabo observación participante en asambleas, foros, rituales o ceremonias de distintas agrupaciones religiosas cristianas, para después realizar las entrevistas en profundidad de manera presencial o vía telefónica, previo acuerdo de comunicación.

Acepto que habría otras lecturas de la información elaborada; en las páginas que siguen ofrezco mi interpretación vigilante (Bourdieu, 2002), que es mi aporte.

\section{RESULTADOS}

\section{Ecos de la biografía de Teresa Forcades}

En los medios de comunicación distintas voces la etiquetan como "monja abortista", "monja mediática", "monja indignada", "la monja más radical de Cataluña", "la monja separatista", "el escándalo eclesial", "la atea vestida de monja", "sor rebelde", "la monjita" o "la supermonja". En su página web, ella se presenta a sí misma: "Teresa Forcades es monja benedictina en el Monasterio de Sant Benet de Montserrat.” Su autoadscricpión a la comunidad benedictina prevalece por encima de sus dichos y hechos en su historia.

La información sobre su biografía es escasa, perfilada apenas en libros y entrevistas. Que nació en 1966, en Barcelona, en una familia de clase media trabajadora "no muy católica"; que su madre es enfermera, su abuelo materno era médico del pueblo y el hermano mayor de su madre, traumatólogo; o que en su escuela primaria, la Escuela Pau Casals del barrio de Gracia, le transmitieron la ilusión por crear un mundo con mayor justicia (Tort, 2013: 36; 96-97). Leyó los evangelios por primera vez a los 15 años y después a Leonardo Boff; hasta entonces había ido al templo "sólo para bautizos y comuniones" (Trucco, 2015). Su trayectoria es pública y notoria a partir de la difusión en youtube de un video titulado "Campanas por la gripe A" (2009), en el que expone su opinión contra la vacuna.

Estudió medicina y teología tanto en España como en Estados Unidos, y obtuvo con honores sus títulos de doctorado (2015a). Paralelamente, en el 2000, hizo sus primeros votos, mientras que sus votos finales los realizó en 2003. Sobre su vocación religiosa, relata:

Estaba terminando mi maestría en medicina y necesitaba un lugar tranquilo para preparar la tesis. Busqué hospitalidad en el famoso monasterio de Montserrat, pero no había lugar, y uno de los monjes benedictinos sugirió que viniera con las monjas. Al principio yo no quería, me imaginaba que el lugar era triste y las monjas aburridas. Entonces me di cuenta de que caía en una contradicción: yo feminista daba por sentado que las monjas no podían ser interesantes. Así que acepté el reto. Al llegar aquí me encontré con una comunidad muy interesante, y después de un mes de estudio, yo, que no venía a convertirme en monja, 
no por vocación, sino sólo para preparar un examen, escuché algo que creció en mí: era la llamada de Dios (en Trucco, 2015).

Aunque en octubre de 2009 fue amonestada debido a sus declaraciones en la televisión catalana a favor de la autodeterminación de las mujeres sobre su propia maternidad, afirma que su comunidad benedictina es plural:

Fue muy significativo que, cuando ocurrió la controversia sobre el aborto y yo hice unas declaraciones, la comunidad se reunió para estudiar el documento que yo pensaba publicar en mi nombre, sin responsabilizar a nadie más. La abadesa me dijo que más o menos la mitad de la comunidad no estaba de acuerdo con lo que yo exponía en ese documento, y que la otra mitad no lo había entendido, pero que tanto las unas como las otras estaban de acuerdo en que querían una Iglesia en la que cada una pueda decir lo que piensa (en Bastante, 2013).

Ha escrito numerosos libros y artículos sobre medicina y teología, ha participado en foros, congresos y asociaciones nacionales e internacionales, además de conducir talleres en su Monasterio.

Pero su teología se deja ver también en su acción política. En 2013 fundó, junto con Arcadi Oliveres, ${ }^{3}$ la plataforma popular "Procés Constituent a Catalunya", cuyo propósito es impulsar "desde abajo" un proceso democrático y pacífico en el que el pueblo catalán decida qué modelo de Estado y de

3 Arcadi Olivares i Boadella (Barcelona, 1945) es un economista, catedrático y activista catalán. Desde la década de los sesenta participa en asociaciones cristianas y movimientos a favor de los derechos humanos, la justicia social y la independencia de Cataluña. país desea; "una iniciativa de cambio a favor de un modelo social, económico y político igualitario y participativo que se niega a separar la Libertad de la Justicia y de la Solidaridad" (Oliveres y Forcades, 2013). El objetivo no fue crear un nuevo partido político sino articular una candidatura unitaria, en el marco de las elecciones al Parlamento de Cataluña, que convocara a una asamblea constituyente; dicha asamblea redactaría una nueva Constitución para la República Catalana a favor de las necesidades de la mayoría y no de los intereses de unos cuantos.

Ante la dificultad de alcanzar esta "candidatura rupturista de unidad" entre sus interlocutores políticos "de izquierdas" y al interior del propio Procés, y aunque la hermana Teresa había señalado en el citado Manifiesto que ninguna de las dos personas que lo presentaban pensaban concurrir a elecciones, el 17 de mayo de 2015 se publicó una carta dirigida a sus asambleas en donde se abrió la posibilidad de que ella dejara el convento temporalmente mediante un "permiso", "dispensa" o "exclaustración” por un año o máximo tres, para ser candidata a las elecciones parlamentarias del 27 de septiembre del mismo año. En Asamblea General realizada el 14 de junio, el Procés dio su apoyo, con 366 votos (73\%), a la "Confluencia por un Proceso Constituyente Popular en Cataluña", propuesta política que contemplaba la candidatura de Forcades (Procés Constituent, 2015). Su exclaustración comenzó un día después de esta asamblea. Tres semanas antes, en las elecciones municipales del 24 de mayo, Ada Colau se había convertido en alcaldesa de Barcelona encabezando la coalición "Barcelona en Común", con el aval de 176 mil sufragios (El País, 2015). 
No obstante, la iniciativa de Forcades por una "candidatura de confluencia rupturista" entre Procés Constituent, Candidatura de Unidad Popular-CUP, Iniciativa por Cataluña Verde-Izquierda Unida y Alternativa-ICV-EUiA y Podemos, no se concretó debido a divergencias organizativas e ideológicas: por un lado, se afirmaba que sólo una declaración unilateral de independencia pondría en marcha un proceso para elaborar una Constitución catalana soberana y, por otro, se argumentaba que esta decisión debía tomarse al final del proceso: ¿independentismo radical o democracia participativa? Sorpresivamente para sus simpatizantes, y aunque Forcades declaró su intención de encabezar una candidatura en solitario por el Procés, el 25 de julio los miembros del movimiento decidieron no sumarse a la candidatura de confluencia "Cataluña sí se Puede" (220 votos, $60.6 \%$ ), y tampoco concurrir a elecciones (214 votos, $67.9 \%$ ), ni en alianza con las CUP (60 votos), ni con una candidatura propia ( 35 votos), esta última liderada por Forcades (Procés, 2015a).

A diferencia del "Proceso participativo" del 9 de noviembre de 2014, en donde más de dos millones de personas se manifestaron a favor de que Cataluña sea un Estado independiente (Generalitat de Catalunya, 2014), los resultados del 27S no dejaron ver con claridad la elección de la sociedad catalana respecto de su futuro nacional y social. Con una participación histórica de más de cuatro millones de personas, 77.4\% del padrón (Generalitat de Catalunya, 2015), la balanza se inclina a favor de la independencia, pero por escaños y no por votos. De momento, la declaración unilateral de independencia se aplaza, pero el proceso soberanista continúa.
Del monasterio a la plaza pública, Forcades aún confía en ser lideresa que active la "subjetivación política" de las y los ciudadanos: el "poder popular" se expresa no sólo a través de las elecciones o el referéndum, sino de la huelga general y la desobediencia civil institucionalizada. En su hoja de ruta, el resultado electoral del $27 \mathrm{~S}$ podría ser el principio de una revolución "pacífica y democrática", "vía lenta para madurar un proceso político", no sólo por la independencia de Cataluña y el reconocimiento de las nacionalidades históricas, sino para romper con el modelo socioeconómico neoliberal y en la búsqueda de un sistema más justo y equitativo (Forcades, 2015c).

Aunque no se ha hecho pública la respuesta del Vaticano en torno a su exclaustración, ella se ha quitado el velo, pero mantendrá sus votos y regresará al Monasterio de tanto en tanto hasta concluir su actividad política. Ante las críticas, responde, siguiendo a Simone Weil y Dorothy Day, que no es posible separar la experiencia del Dios cristiano del compromiso social público por la justicia (Forcades, 2015b); "hay que hacer la revolución y volverla a hacer".

Con una página web oficial, canal de youtube, cuenta de twitter, página de Facebook, y presentaciones en radio y televisión, Teresa Forcades es persona en el mundo contemporáneo. A un tiempo intenta rebasar el secularismo excluyente y seguir la vida monástica. Se comunica en español, inglés y alemán, pero habla en catalán desde un talante de apertura a la diversidad. Entre la medicina, la teología y la política, es una monja benedictina del siglo XXI cuyo monasterio es el mundo. Encontrando raíces en la Regla de San Benito y en su comunidad, abre 
las puertas del claustro y participa en movimientos de cambio social. Sin dejar de autoadscribirse a una Iglesia estructural que considera misógina y patriarcal, es teóloga feminista, lideresa para servir, médica que denuncia, monja exclaustrada, persona en comunidad.

Con base en estos apuntes en torno a su biografía y contexto, en los apartados siguientes comento cuestiones fundamentales sobre su teología feminista vinculadas con el enfoque de género.

\section{La teología feminista ${ }^{4}$ de Teresa Forcades}

La Iglesia está orgullosa, vosotras los sabéis, de haber elevado y liberado a la mujer, de haber hecho resplandecer, en el curso de los siglos, dentro de la diversidad de los caracteres, su innata igualdad con el hombre (...) Velad, os lo suplicamos, por el porvenir de nuestra especie.

Pablo VI, Mensaje a las mujeres, Concilio Vaticano II, 8 de diciembre de 1965

Es hasta el siglo XX cuando la teología feminista rompe con la teología "tradicional" del siglo I

4 Dada la extensión de este trabajo, así como el debate académico y social en torno a las categorías de "mujer", "persona" e "identidad" — por ejemplo, respecto de la Interrupción Legal del Embarazo o sobre la defensa del derecho a la identidad de género elegida por personas "trans"-, defino operativamente "teología feminista" como aquella teología crítica de la liberación hecha no sólo por mujeres-sujeto que leen, interpretan y recrean la "Palabra de Dios" o su experiencia íntima sobre la "Divinidad" no confundir teología femenina con teología feminista-, sino por personas de identidades diversas que reflexionan desde una perspectiva crítica de género, sobre todas las contradicciones sociales — no sólo sobre las problemáticas vinculadas a la "fe", a la "Divinidad" o a las "mujeres"con base en alguna tradición religioso/espiritual, y cuya reflexión puede o no derivar en alguna modalidad de activismo social o político. y posteriores - patrística, oriental, escolástica, protestante-luterana y moderna- (Vilanova, 1992), en la que sólo los hombres tenían la facultad de entender, a través del intelecto, la "Fe" o la "Palabra de Dios". Esta nueva teología, desarrollada en el marco del Concilio Vaticano II, se opone igualmente a la "teología sobre la mujer”, que discernía con mirada androcéntrica la "Palabra de Dios" en torno al denominado "problema de la mujer".

La teología feminista se vislumbra hoy como "tradición viva" en desarrollo (Vilanova, 1992: 38) y como campo de estudio en proceso de institucionalización académica (Schüssler Fiorenza, 2004). Denuncia la exclusión, la discriminación y la marginalidad de las mujeres en la Iglesia Católica y en la vida social, fundada en interpretaciones "desfavorables" de la Biblia, contribuyendo por este camino a su liberación (Bernabé, 1998: 13-30).

Continuando el sostenido y sistemático trabajo de "reflexión sobre su fe" que teólogas feministas han realizado a lo largo del siglo XX y XXI (Heinzelmann, Radford Ruether, Daly, Rusell, Schüssler Fiorenza o Raming), pero también siguiendo los pasos de precursoras "invisibles" que desde la era patrística se expresaron a la par de la "teología patriarcal" (Tecla, Macrina la joven), Forcades comprende la teología feminista como una teología crítica de liberación, que surge a partir de las múltiples experiencias de contradicción que la persona identifica entre su propia vivencia de Dios y las Escrituras, o su interpretación (Forcades, 2011: 13-20). 
Feminismo de la igualdad

o feminismo de la diferencia

En reconciliación de los extremos entre autoras clásicas de los estudios de género, Forcades acepta que "el feminismo de la diferencia percibe correctamente el punto de partida de nuestro trayecto vital como personas: nuestro punto de partida está determinado por el sexo; y el feminismo de la igualdad percibe correctamente el punto de llegada: nuestro punto de llegada está libre de toda determinación, incluída la sexual" (Forcades, 2009: 39).

Dado que no existen dos únicos sexos, complementarios, dicotómicos y jerarquizados, dado que el género es performativo, y dado que deseo e identificación no tienen por qué ser mutuamente excluyentes ni unívocos (Butler, 2007), coincide con feministas y estudiosas del género que desplazan las nociones naturalizadas y reificadas en las que se sustenta la hegemonía masculina y el poder heterosexista. En estas líneas precisa:

El feminismo cristiano reconoce las categorías de "mujer" y "varón" y reconoce como "reales" las diferencias corporales que han originado estas categorías, pero a la vez afirma que la plenitud humana no pasa por la pareja, ni pasa por la afirmación esencializada de las categorías de sexo y género, a las cuales considera necesariamente como penúltimas y como destinadas a ser superadas en la plenitud de la originalidad irreductible del ser personal, experimentable solamente en las relaciones interpersonales amorosas y libres, abiertas a todos, que deberían caracterizar la comunidad eclesial (Forcades, 2012: 10).

Con base en Lacan, deduce que el género existe, pero estamos llamados a trascenderlo para descubrirnos como personas. Es necesario atravesar la "fantasía primordial" para estar en el mundo como identidades abiertas, en permanente proceso de transformación.

\section{Relacionalidad de libertades}

Forcades articula avances del feminismo y de los estudios de género para elaborar su teología feminista sobre una relación, ya no de dominación y dependencia entre "autoridad" y "criatura", sino como una relación horizontal, "amorosa", "de iguales", "de tú a tú”, contraria al modelo patriarcal, saboreándola desde su cotidiana vivencia:

Para mí fue un momento muy importante, como si Dios me viniera a decir que no limitara a mis prejuicios la comprensión de hasta qué punto era radical la propuesta de comunión, de intercambio amoroso que Dios nos hace a cada una y cada uno. Decía Dios: ¿tú aún no has salido de estas categorías humanas? Las vas contraponiendo: divino-humano, sagrado-profano, María humana, Dios divino, Jesús divino... Una jerarquía. ¿Pero no te das cuenta que la interpretación, el sentido, la consecuencia de mi encarnación es precisamente que esa separación jerárquica entre lo humano y lo divino no existe más? Yo no quiero llamaros sirvientes, yo os llamo amigos. Precisamente esa experiencia profunda es de Dios diciendo: ¿no has entendido aún ese mensaje radical que yo he venido a traer? ¿No con palabras sino con mi vida, encarnación y muerte? Queda abolida esa diferencia jerárquica entre divino y humano, que es comunión, y que esa relación amorosa es una relación de iguales (Forcades, entrevista telefónica, 17 de diciembre 2014).

Siguiendo con la analogía psicoanalítica, profundiza: "Dios no es un soberano solitario que encarna el delirio de omnipotencia infantil del psicótico: es una comunidad, una relacionalidad 
de libertades" (Grenzner, 2014). En consecuencia, tenemos que apartarnos de la noción de persona como ser autónomo que se concibe a sí mismo con independencia de su relacionalidad.

\section{De la "subjetivación infantil" a ser "persona"}

Para Forcades la sociedad patriarcal la construimos hombres y mujeres juntos cuando en la vida adulta vivimos en continuidad con el patrón de subjetivación infantil, que tiene como referente a la figura materna, y que da lugar a una estructura psíquica distintiva según el género. Sin embargo, es posible "volver a nacer" trascendiendo las identidades de género socialmente establecidas, abriéndonos a una subjetividad que tenga como referente no a la figura materna sino, en el caso de la persona creyente, a Dios, o en el caso de la no creyente, a cualquier "horizonte" que le permita subjetivarse sin dicotomía de género:

Ser "persona" es ser capaz de vivir en comunión como lo hacen el Padre, el Hijo y el Espíritu. Experimentar esta comunión no implica que la plenitud de mi ser persona deba concretarse en una relación heterosexual que me complemente, ni significa tampoco que tenga que hacerme hermafrodita a fin de llegar a ser a la vez varón y mujer. Lo que significa es que, a fin de lograr nuestra realización personal necesitamos reconocer el carácter ilusorio de nuestras identidades de género y trascenderlas - en palabras de Lacan "atravesar la fantasía primordial”- ; esto es, avanzar más allá de los procesos infantiles de individuación que tienden a reducir nuestro ser personal (creado a imagen de Dios como ser único capaz de relacionarse con los demás gratuita y recíprocamente), a los estereotipos de género de la "feminidad" (una supuesta capacidad para "amar" que excede nuestra capacidad de ser "libres"), o de la "masculinidad" (una supuesta capacidad de "ser libres" que excede nuestra capacidad para "amar") (Forcades, 2009: 23-24).

La subjetivación adulta no necesita ningún requerimiento externo, por el contrario, es responsabilidad plena de tus circunstancias. En ello está implícito el miedo a la libertad, pero cada persona está llamada a ser "pieza única":

¿Es cultural o es biológico? ¿Cómo lo vemos? La propuesta que les hago, y esta ya es la propuesta teológica, es la de trascender la distinción femenino/ masculino, de concebir esa distinción como algo real, pero llamado a ser superado. El género existe, pero estamos llamados a trascender el género. La feminidad y la masculinidad existen, pero estamos llamados a superarlas. Eso quiere decir que la diferencia de género es un punto de partida antropológico - con todas las variantes, ¿eh?, no es una cosa fija, pero es un punto de partida-, que va a tener mucho de cultural y que tendremos que negociar, pero no es nuestro punto de llegada cristológico (Forcades, 2006: 22).

El filósofo feminista Paul B. Preciado, quien la califica como "disidente dentro de la Iglesia", del mismo modo que él lo es dentro del lesbianismo, asegura que la teología de Forcades no es queer; y al respecto la interroga:

¿Dónde quedamos los intersexuales, los transexuales, los "otros" en tu teología? [...] Me sorprende que en tu teología elijas partir del binarismo femenino/ masculino, que es una construcción normativa, en lugar de partir de la irreductible multiplicidad del cuerpo en todas sus variables, y si quieres, por decirlo en tu lenguaje, Dios podría encarnarse en todas ellas (Preciado, 2014: 25, en Valdés, 2014). 
Ella replica que justamente ese es el punto de llegada, pues reconocer la dicotomía de género es la estrategia más potente para desactivarla después.

Si bien Forcades argumenta a detalle en sus diversos escritos sobre asuntos fundamentales como la misoginia de la jerarquía católica, el sacerdocio femenino, la Biblia feminista, la Asamblea como forma de organización $y$ participación política "desde abajo" o la idea de Dios como Madre, dejamos hasta aquí esta aproximación para trazar algunas conclusiones preliminares.

\section{CONCLUSIONES Y PROSECUSIONES}

Lo que define la humanidad adulta de Cristo no son sus determinantes biológicos

(cromosomas, gónadas, sexo u hormonas), tampoco sus determinantes psíquicos ni sociales, sino lo que él hace con estos determinantes, la manera como los asume para realizar con ellos y desde ellos actos de amor libre que son los únicos que expresan en acto la potencialidad de su esencia.

Teresa Forcades

Debido a que posee bases sólidas en autores clásicos pero también contemporáneos, la teología feminista de Teresa Forcades articula de manera novedosa el feminismo y el enfoque de género, valiéndose del lenguaje teológico, para responder a problemáticas sociales urgentes.

Queda pendiente la tarea de estudiar a fondo su aporte específico en relación con las ideas de autoras clásicas de los estudios de género, pero también en diálogo con las precursoras de la teología feminista, en donde anticipamos hay numerosos elementos en común. Otro campo de exploración en curso es sobre las consecuencias políticas de su teología feminista, en donde advertimos ya algunas tensiones - nacionalismo catalán y "asamblea de iguales". Habrá que dar seguimiento también a la manera en la que su teología feminista se desarrollará a partir de su experiencia en el Procés y los resultados del 27S. Y resultará interesante comparar su teología feminista con otras tradiciones religioso/ espirituales contemporáneas que parecen cuestionar las identidades heteronormativas $\mathrm{y}$ empoderar a las mujeres.

Según Rubin (1975), la "evolución cultural" ofrece la oportunidad de tomar decisiones para liberar la vida humana de patrones arcaicos determinados por el género. Ante los feminismos radicales que hoy rechazan la reproducción de estereotipos y roles por parte de personas que no se identifican con las identidades genéricas de hombre o mujer, o bien, frente a la condena de la Iglesia católica al matrimonio igualitario en México, considero que tanto la respuesta desde la perspectiva "trans" como la "feminista" son necesarias en un proceso de reconocimiento identitario, individual y colectivo, que sea capaz de rebasar plenamente cultura y biología como destino.

Las palabras y acciones de esta monja benedictina, con su teología feminista y su liderazgo político, hablan; sus ecos resuenan cada vez más como una figura que se destaca por sus pasajes disidentes entre las esferas religiosa, política y social. Tránsitos no arcaicos ni obsoletos, sino necesarios y posibles en este siglo XXI. ¿े 


\section{BIBLIOGRAFÍA}

Bastante, Jesús (2013), “Teresa Forcades: 'En la Iglesia se palpan el clericalismo institucionalizado y la misoginia estructural"”, en Religión digital, consultado el 27 de mayo de 2015, URL:

http://www.periodistadigital.com/religion/libros/2013/04/18/teresa-forcades-en-la-iglesia-se-palpan-elclericalismo-institucionalizado-y-la-misoginia-estructural-religion-iglesia-libros-dau.shtml

Berger, Peter (2012), "Further Thoughts on Religion and Modernity”, en Society, 49 (9), pp. 313-316.

Berger, Peter (2001), "Reflections on the Sociology of Religion Today", en Sociology of Religion, 62 (4), pp. 443-454.

Bernabé, Carmen (1998), “La Biblia”, en Mercedes Navarro (coord.), 10 mujeres escriben teología. Navarra, Estella, pp. 13-30.

Blancarte, Roberto (2010), "Las identidades religiosas de los mexicanos”, en Roberto Blancarte (coord.), Los grandes problemas de México, vol.16, Culturas e identidades. México, El Colegio de México, pp. 87-114.

Bourdieu, Pierre, Jean-Claude Chamboredon y Jean-Claude Passeron (2002), El oficio de sociólogo. Buenos Aires, Siglo XXI.

Butler, Judith (2007), El género en disputa: el feminismo y la subversión de la identidad. Barcelona, Paidós.

Curia, Dolores (2015), "La importancia de llamarse Paul”, en Página 12, Suplemento Soy, consultado el 7 de junio de 2015, URL: http://www.pagina12.com.ar/diario/suplementos/soy/1-4022-2015-0606.html

Dussel, Enrique (2005), Transmodernidad e interculturalidad, interpretación desde la Filosofía de la Liberación. México, UAM-Iztapalapa.

El País (2015), “24M Elecciones. Resultados. Elecciones municipales 2015. Barcelona”, en El País, consultado el 27 de mayo de 2015, URL:

http://resultados.elpais.com/elecciones/2015/municipales/09/08/19.html 
Forcades, Teresa (2006), “Existe lo femenino en Dios?”, Foro de Vitoria Gasteiz, Resumen elaborado por el Foro, consultado el 23 de mayo de 2014, URL:

https://teresaforcades.files.wordpress.com/2014/07/lo-femenino-en-dios.pdf

Forcades, Teresa (2009), "Hacia una sociedad de iguales", en IViva-Iglesia Viva, Revista de pensamiento cristiano, num. 239, consultado el 7 de marzo de 2015, URL:

http://dialnet.unirioja.es/servlet/articulo?codigo=3063719

Forcades, Teresa (2011), La teología feminista en la historia. Barcelona, Fragmenta.

Forcades, Teresa (2012), “Cristianismo, género y cambio social. Una perspectiva feminista católica”, en IViva-Iglesia Viva, Revista de pensamiento cristiano Iglesia, núm. 251, consultado el 7 de marzo de 2015, URL: https://teresaforcades.files.wordpress.com/2014/08/cristianisme-gc3a8nere-i-canvi-social.pdf

Forcades, Teresa (2015a), “Teresa Forcades i Vila. Página web oficial”, consultada el 14 de abril de 2015, URL: http://teresaforcades.com/

Forcades, Teresa (2015b), Por amor a la justicia. Dorothy Day y Simone Weil. Barcelona, Ediciones HOAC.

Forcades, Teresa (2015c), "Foro Unidad popular y asalto a las instituciones", consultado el 20 de agosto de 2015, URL: https://www.youtube.com/watch?t=1834\&v=dHmqmasQkAw

Generalitat de Catalunya (2014), "Resultados definitivos del proceso de participación del 9N”, consultado el 23 de marzo de 2015, URL:

http://web.gencat.cat/es/actualitat/detall/Resultats-definitius-del-proces-de-participacio-del-9N-00001

Generalitat de Catalunya (2015), "Eleccions al Parlament de Catalunya 2015”, consultado el 29 de septiembre de 2015, URL: http://resultats.parlament2015.cat/09AU/DAU09999CM_L1.htm

Grenzner, Joana G. (2014), “Cuando no obedeces a intereses claros, eres incómoda para unos y otros”, en Pikara magazine, consultado el 1 de agosto de 2015, URL: http://www.pikaramagazine.com/2014/01/ cuando-no-obedeces-a-intereses-claros-eres-incomoda-para-unos-y-otros/

Hervieu-Léger, Danièle (2005), La religión, hilo de memoria. Barcelona, Herder. 
Hervieu-Léger, Danièle (2006), "In Search of Certainties: The Paradoxes of Religiosity in Societies of High Modernity", en Hedgehog Review, vol. 8, núm 1-2, pp. 59-68.

Juárez, Elizabeth y Diana Ávila (2007), "Perfiles demográficos de la diversidad religiosa”, en Renée De la Torre y Cristina Gutiérrez (coord.), Atlas de la diversidad religiosa en México. México, CIESAS, Secretaría de Gobernación, CONACYT.

Lagarde, Marcela (2012 [2010]), “Epistemología feminista para la formación de lideresas”, en Lagarde, Marcela, El feminismo en mi vida. Hitos, claves y topías, México: Inmujeres DF/GDF.

Lagarde, Marcela (2012 [1996]), "La construcción de las humanas: Identidad de género y derechos humanos", en Marcela Lagarde, El feminismo en mi vida. Hitos, claves y topías. México, Inmujeres DF/GDF.

Löwy, Michael (2013), "Walter Benjamín: el materialismo mesiánico”, conferencia (en diálogo con Enrique Dussel), Universidad Autónoma de la Ciudad de México, Plantel del Valle, 25 de abril de 2013, México, D.F.

Oliveres, Arcadi y Teresa, Forcades (2013), "Manifest per la convocatòria d'un Procés Constituent a Catalunya", consultado el 21 de febrero de 2014, URL: http://www.ara.cat/politica/ProcesConstituent-incorporar-se-Catalunya-Pot_0_1400260184.html

PEW Research Center (2012), “The Global Religious Landscape”, Washington, D.C., consultado el 27 de agosto de 2014, URL: http://www.pewforum.org/2012/12/18/global-religious-landscape-exec/

Preciado, Beatriz (2011), Manifiesto Contrasexual. Barcelona, Anagrama.

Procés Constituent (2015), “Assemblea General-\#FemProcés”, consultado el 14 junio de 2015, URL: https://www.youtube.com/watch?v=i_XJ2Z0QnKw\&feature=youtu.be

Procés Constituent (2015a), "Procés Constituent no es presentarà a les eleccions del 27-S", consultado el 25 de julio de 2015, URL:

http://www.procesconstituent.cat/ca/blog/item/proces-constituent-no-es-presentara-a-les-eleccions-del-27-s 
Rubin, Gayle (1996 [1975]), “El tráfico de mujeres: notas sobre la 'economía política' del sexo”, en Marta Lamas, El género: la construcción cultural de la diferencia sexual. México, PUEG-UNAM, pp. 48-74.

Schüssler Fiorenza, Elisabeth (2004), Los caminos de la sabiduría. Santander, Sal Terrae.

Scott, Joan (2006 [2001]), "El eco de la fantasía: la historia y la construcción de la identidad", en Ayer, núm. 62 (2), pp. 284-304.

Tort, Eulalia (2013), Diálogos con Teresa Forcades. Barcelona, Dau.

Trucco, Roberta (2015), “Teresa, monaca: la Chiesa è misogina ma Dio è anche donna”, en Corriere della Sera, consultado el 8 de junio de 2015, URL: http://27esimaora.corriere.it/articolo/teresa-monaca-lachiesa-e-misogina-ma-dio-e-anche-donna/

Valdés, Andrea (2014), "Encarnar diferencias. Beatriz Preciado \& Teresa Forcades conversan con Andrea Valdés", en El Estado Mental, núm 2, junio 2014, consultado el 23 de mayo de 2015, URL: https:// teresaforcades.files.wordpress.com/2014/08/encarnar-disidencias.pdf

Vilanova, Evangelista (1992), "Historia y teología", en Evangelista Vilanova, Para comprender la teología. Madrid, Verbo Divino, pp. 37-49.

Fecha de recepción: 29 de agosto de 2015

Fecha de aceptación: 21 de septiembre de 2015 